\title{
Heritability and correlation analysis of morphological and yield traits in genetically modified cotton
}

\author{
REHMAN Abdul ${ }^{1,2}$, MUSTAFA Nida ${ }^{3}$, DU Xiongming ${ }^{1,2}$ and AZHAR Muhammad Tehseen ${ }^{3,4^{*}}$ (D)
}

\begin{abstract}
Background: Cotton is known for fiber extraction and it is grown in tropical and sub-tropical areas of the world due to having hot weather. Cotton crop has a significant role in GDP of Pakistan. Therefore, the two-years research was conducted to estimate heritability and association among various yield contributing parameters of cotton, i.e., plant height, number of bolls per plant, number of sympodial branches per plant, seed cotton yield, boll weight, seed index, ginning outturn (GOT), fiber length, fiber strength, and fiber fineness.

Results: Association analysis revealed that seed cotton yield had a significant positive correlation with plant height, number of bolls per plant, number of sympodial branches per plant, GOT, staple length and fiber strength. Staple length and fiber strength were negatively linked with each other. Estimates of heritability were high for all of the traits except the number of sympodial branches per plant and boll weight.

Conclusion: The parent IUB-222 was found to be the best for plant height, the number of bolls per plant, boll weight, GOT, seed cotton yield, and seed index. The genotypes namely, NIAB-414 and VH-367 were identified as the best parents for fiber length, strength, and fineness. Among the crosses NIAB-414 $\times$ IUB-222 was the best for the number of bolls per plant, seed index, seed cotton yield and fiber fineness, whereas, the cross of NIAB-414 $\times$ CIM-632 was good for plant height. The combination of A555 $\times$ CIM-632 was the best for the number of sympodial branches per plant, boll weight, fiber length, and strength, and VH-367 $\times \mathrm{CIM}-632$ proved the best for GOT.
\end{abstract}

Keywords: Genetic correlation, Genetic variability, Inheritance, Productivity, Upland cotton

\section{Introduction}

Cotton is also known as white gold due to its white and soft fiber, also called vegetable fiber. The cotton plant was grown like a shrub in nature and its fiber is pure cellulose. The cotton fiber is used to spin into yarn which is further used for making socks, curtains, and towels, etc. Its fiber also consumed in textile industry for cloth making (Stewart and Rossi 2010). A significant amount of oil (16\% 27\%) is extracted from cotton seed

\footnotetext{
* Correspondence: tehseenazhar@gmail.com

${ }^{3}$ Department of Plant Breeding and Genetics, University of Agriculture

Faisalabad, Faisalabad 38040, Pakistan

${ }^{4}$ School of Agriculture Sciences, Zhengzhou University, Zhengzhou 450001,

China

Full list of author information is available at the end of the article
}

and seed cake is used in the livestock industry. The oil extracted from cotton seed is used as vegetable oil for making fries etc. because the taste of cottonseed oil is similar to coconut oil. In addition, it is an important source of vitamins, fat, and antioxidants (Dowd et al. 2010). During the 2018-2019 survey, cotton was cultivated on an area of 2373 thousand hectares with 9.861 million bales production. It shares $0.8 \%$ in GDP and $4.5 \%$ in value addition (Economic Adviser's Wing 2019).

The world population is increasing day by day; therefore, it is necessary to increase the productivity of crops to meet the requirement of textile industry. The utilization of various breeding tools is one method to meet the demand of textile industry (Farooq et al. 2014). Understanding the genetic basis of important yield contributing traits

(c) The Author(s). 2020 Open Access This article is licensed under a Creative Commons Attribution 4.0 International License, which permits use, sharing, adaptation, distribution and reproduction in any medium or format, as long as you give appropriate credit to the original author(s) and the source, provide a link to the Creative Commons licence, and indicate if changes were made. The images or other third party material in this article are included in the article's Creative Commons licence, unless indicated otherwise in a credit line to the material. If material is not included in the article's Creative Commons licence and your intended use is not permitted by statutory regulation or exceeds the permitted use, you will need to obtain permission directly from the copyright holder. To view a copy of this licence, visit http://creativecommons.org/licenses/by/4.0/. 
is the pre-requisite and information about their relationship must be available to cotton breeders. All of the yieldrelated traits are correlated with each other in a way that increases or decreases in one trait directly affects others. So, estimation of genotypic and phenotypic correlations among these traits are helpful to initiate the breeding programs. The knowledge about association among various plant characters is useful in the selection of appropriate breeding methods (Teklewold et al. 2000). Phenotypic correlation shows the visual observation while genotypic correlation estimates the inheritance of characters (Desalegn et al. 2009). It was indicated that the number of bolls and the number of sympodial branches per plant were positively linked with each other. The weight of a boll had a negative relationship with the number of bolls per plant. Seed cotton yield and number of bolls were also positively correlated with each other. Heritability values were also high for these traits (Shar et al. 2017). Investigations revealed that association and inheritance for various quantitative and fiber related parameters of American cotton (Haq et al. 2017). In addition, the yield of seed cotton was positively linked with plant height, sympodial branches, monopodial branches, and bolls per plant whereas negatively correlated with days to $1^{\text {st }}$ flowering. While seed cotton yield had a positive correlation with 100-seed weight, the number of bolls per plant, plant height, and boll weight (Memon et al. 2017; Mukoyi et al. 2018). Lint index, number of bolls per plant, boll weight, sympodial branches per plant, and GOT exhibited positive linkage with the yield of seed cotton per plant. Heritability was high for the number of bolls per plant, monopodial branches per plant, internode distance, and sympodial branches per plant (Monisha et al. 2018). High heritability and positive correlation were reported for monopodia per plant, the number of bolls per plant, yield of seed cotton, and fiber fineness (Khokhar et al. 2017; Komala et al. 2018). Positive correlation and high heritability were observed for plant height, sympodial branches, the number of bolls, boll weight, seed cotton yield, and fiber fineness. Hence, it is concluded that these traits may be considered as selection criteria for improvement in seed cotton yield (Jarwar et al. 2018; Rathinavel et al. 2017). The presented research was planned to determine the correlation among various yield contributing traits due to the increasing demand for cotton in the country. The heritability of these parameters was also computed which could be used for the selection of suitable traits from certain parents for the development of new germplasm of upland cotton.

\section{Materials and methods}

The experiment was performed at two places, first in a glasshouse and then in the cotton research area of the Department of Plant Breeding and Genetics, University of Agriculture, (latitude $31^{\circ} 25^{\prime} \mathrm{N}$, longitude $73^{\circ} 09^{\prime} \mathrm{E}$, and altitude $184.4 \mathrm{~m}$ from sea level) Faisalabad, Pakistan. Experimental material was collected from Cotton Research Group of the Department of Plant Breeding and Genetics, University of Agriculture, Faisalabad, Pakistan. Five genotypes, namely A-555, IUB-222, VH-367, NIAB- 414, and CIM-632 were grown in earthen pots during November 2017 in greenhouse conditions available with the department. The optimal growing conditions, i.e., temperature $\left(25 \sim 35^{\circ} \mathrm{C}\right)$ light intensity (25 $000 \sim 30000 \mathrm{~lx})$ and humidity $(44 \% \sim 49 \%)$ were maintained for germination and growth of the plants. At the two-leaf stage, one healthy seedling per pot was kept while others were thinned. These five parents were crossed to make all possible combinations in full diallel at the appearance of buds. Some of the buds from parents were selfed. Later, cotton seed from 20 crosses along with their parents were picked, ginned, and sown at a cotton farm during the second week of May 2018. The parents along with the $F_{1}$ population planted in three replications followed by randomized complete block design (RCBD). Row to row and plant to plant distance was $75 \mathrm{~cm}$ and $30 \mathrm{~cm}$, respectively. All agronomic practices were followed from sowing to harvesting to get a good and healthy plant population. Following parameters of cotton plants were noted at various time intervals and the protocol of each trait is mentioned in the following paragraphs.

\section{Plant height (cm)}

Plant height was measured in $\mathrm{cm}$ with the help of a measuring rod. The height was measured from the first cotyledonary node to the apical bud at maturity. The average height of seven guarded plants was calculated in each family.

\section{The number of bolls per plant}

Fully opened bolls were picked and recorded from all the replications of each family. The averagenumber of bolls was calculated for each parent/cross for data analysis.

\section{The number of sympodial branches per plant}

At maturity, the number of sympodial branches of seven guarded plants was counted manually in each replication, and then the average values were calculated for each parent/cross.

\section{Seed cotton yield $(g)$}

Seed cotton was picked from maturely opened bolls from seven guarded plants. All seed cotton picked were cumulatively weighed by using an electronic balance. The average seed cotton yield was calculated for each parent/cross for use in the analysis. 


\section{Boll weight ( $g$ )}

Boll weight was obtained by dividing the weight of seed cotton yield from each plant by the number of bolls per plant. The average boll weight was calculated for each genotype for biometrical analysis.

\section{Seed index ( $g$ )}

Seed index determined from the 100-seed weight from each plant. Cotton seeds were separated from each plant by using a single roller ginning machine (McCarthy Roller Gin 1840). A random sample of 100-seeds was obtained from each plant and weighed by using electronic balance to determine the seed index. The mean seed index was calculated for each parent/cross in all replications.

\section{Ginning outturn (\%)}

First seed cotton yield was weighed and then ginned with a single roller electrical gin machine (McCarthy Roller Gin 1840). The lint obtained from each sample was weighed separately. Ginning percentage was calculated by using the formula as proposed by Singh (2004).

$$
\text { Ginning outturn }(G O T \%)=\frac{\text { Weight of lint in a sample }}{\text { Weight of seed cotton in a sample }} \times 100
$$

\section{Fiber length $(\mathrm{mm})$, fiber strength $\left(g \cdot \mathrm{tex}^{-1}\right)$ and fiber fineness $\left(\mu \mathrm{g} \cdot\right.$ inch $^{-1}$ )}

Fiber traits were measured by high using high volume instrument (Model USTER@ HVI-900 SA) system and means for each parent and cross were calculated.

\section{Statistical approaches}

The data collected were subjected to analysis of variance following the method of Steel and Torrie (1997) to determine the significant differences in plant characters of upland cotton by Minitab Inc., (2010). Standard deviation and standard error were calculated by the following formulae,

$$
\begin{aligned}
& S D=\sqrt{\frac{\sum(\mathrm{X}-\mathrm{M})^{2}}{n-1}} \\
& S E=S D / \sqrt{n}
\end{aligned}
$$

Genotypic and phenotypic correlation among traits were analyzed by a statistical technique that is known as correlation analysis (Kwon and Torrie 1964). Whereas, Heritability in broad sense was estimated according to Burton (1953). Heritability was divided in three classes, i.e., Low heritability $<0.2$, Medium heritability $=0.2-0.5$ and High heritability $>0.5$.

$$
h^{2}{ }_{B S}=\sigma^{2} \mathrm{~g} / \sigma^{2} \mathrm{p}
$$

where,

$\sigma^{2} \mathrm{~g}=$ The genotypic variance.

$\sigma^{2} \mathrm{p}=$ The phenotypic variance.

$h^{2}{ }_{\mathrm{BS}}=$ Heritability broad sense.

\section{Results}

The analysis of variance (ANOVA) exhibited significant differences and confirmed the presence of variations among genotypes for the traits, namely plant height, number of bolls per plant, number of sympodial branches per plant, boll weight, the yield of seed cotton, seed index, fiber length, fiber strength and fiber fineness (Table 1). Later, the data were used for correlation and heritability analysis. The significant results of these traits allowed the researchers to proceed for other biometrical approaches namely, correlation and heritability.

\section{Correlation coefficient analysis}

Correlation coefficient analysis measures the relationship between various plant characters. The estimation of genotypic and phenotypic correlations among the traits help initiate breeding programs. If the correlation between two traits is positive and significant, improvement in one trait will exert a significant impact on the other. Hence, selection for one character will improve other positvely associated traits. In the present study, plant height exhibited positive and significant correlation with the number of bolls per plant, the number of sympodial branches per plant, GOT, seed cotton yield, fiber length, and fiber fineness, repectively, whilst non-significant association with boll weight (Table 2). However, plant height showed a negative but non-significant relationship with fiber strength. The number of bolls per plant showed a positive and significant association with plant height, the number of sympodial branches per plant, boll weight, seed index, seed cotton yield, and fiber strength, repectively, whereas a negative correlation was observed for fiber length. The number of sympodial branches per plant had a positive and significant relationship with all of traits except seed index and staple length. Boll weight had a positive and significant correlation with the number of bolls per plant, the number of sympodial branches per plant, 100-seed weight, staple length, and fiber fineness, respetively, whereas the rest had a positive but non-significant association except GOT, which have a positive and significant linkage with plant height, seed cotton yield, the number of sympodial branches per plant, and fiber length, repectively. It had a positive but non-significant association with the number of bolls per plant. However, GOT had a negative and non-significant correlation with boll weight, 100-seed weight, fiber strength, and fiber fineness, respectively. Seed index had 
Table 1 Analysis of variance of various quantitative traits for $F_{1}$ population and parents in upland cotton formulated by using MINI TAB 16

\begin{tabular}{llllllllllll}
\hline SOV & DF & PH & NB & SB & BW & GOT & SI & SCY & FL & FS & FF \\
\hline Rep. & 2 & $2.21^{\text {ns }}$ & $2.88^{\text {ns }}$ & $4.39^{*}$ & $4.77^{*}$ & $5.88^{\text {ns }}$ & $0.29^{\text {ns }}$ & $4.63^{\text {ns }}$ & $4.65^{*}$ & $5.68^{*}$ & $0.35^{\text {ns }}$ \\
Gen. & 24 & $3.92^{* *}$ & $2.17^{*}$ & $1.93^{*}$ & $1.86^{*}$ & $10.70^{* *}$ & $2.15^{*}$ & $16.21^{* *}$ & $2.13^{*}$ & $2.48^{* *}$ & $3.37^{* *}$ \\
Err. & 48 & - & - & - & - & - & - & - & - & - & -
\end{tabular}

**: Highly significant $(P \leq 0.01)$, : Significant $(P \leq 0.05)$

$\mathrm{PH}$ : plant height, BP: the boll number per plant, SB: the number of sympodial branches per plant, BW: boll weight, SI: seed index, SCY: seed cotton yield, FL: fiber length, FS:fiber strength and FF: fiber fineness

a positive and significant linkage with the number of bolls per plant, boll weight and fiber length while seed index had a positive but non-significant correlation with plant height, the number of sympodial branches per plant, the yield of seed cotton, and fiber fineness. It had a negative and non-significant relationship with GOT and fiber strength, respectively.

Seed cotton yield had a positive and significant association with plant height, the number of bolls per plant, the number of sympodial branches per plant, GOT, staple length, and fiber strength, repectively. Seed index showed a positive but non-significant correlation with boll weight, seed index and fiber fineness, repectively, whereas it has a negative and non-significant association with fiber strength. Fiber length presented a positive and significant linkage with plant height, boll weight, GOT, seed index, fiber fineness, and seed cotton yield, respectively, while a positive but non-significant correlation with the number of sympodial branches per plant. Staple length exhibited a negative and significant association with fiber strength while a negative and non-significant relationship with the number of bolls per plant and fiber fineness, respectively. Fiber strength had a positive and significant association with the number of bolls per plant, the number of sympodial branches per plant, and seed cotton yield, repectively, whereas a positive and non-significant correlation with boll weight, a negative and non-significant relationship with plant height, GOT and seed index, respectively. Fiber fineness had a positive and significant correlation with plant height, the number of sympodial branches per plant, boll weight, and staple length, respectively, whereas a positive and non-significant association with the number of bolls per plant and seed index, respectively. It showed a negative and non-significant linkage with GOT, yield of seed cotton, and fiber strength, respectively.

\section{Estimates of heritability}

Heritability (BS) ranged from medium to high for various yield and fiber traits (Table 3). The traits namely, plant height, the number of bolls per plant, GOT, seed index, seed cotton yield, fiber length, strength, and fineness showed high heritability estimates, i.e., $74.48 \%$, $53.87 \%, 90.65 \%, 53.42 \%, 54.56 \%, 52.95 \%, 59.66 \%$, and $70.42 \%$, respectively. The traits including the number of sympodial branches per plant and boll weight exhibited medium estimates of heritability, i.e., $48.06 \%$ and $46.66 \%$, respectively. The process of selection could be useful for characters with high heritability value.

\section{Mean comparison for metric traits}

Among parents, the genotype A555 had the lowest mean value of $99.93 \mathrm{~cm}$, while CIM-632 exposed maximum mean value of $124.73 \mathrm{~cm}$ in plant height (Fig. 1-A). The hybrid of IUB- $222 \times$ NIAB-414 exhibited minimum mean value of $88.07 \mathrm{~cm}$, whereas NIAB-414 $\times$ CIM-632 showed the highest mean value of $127.2 \mathrm{~cm}$. VH-367 exposed minimum number of bolls per plant with the lowest mean value of 16.26, whereas IUB-222 showed

Table 2 Correlation among various traits of Upland cotton grown in filed conditions by using correlation analysis

\begin{tabular}{|c|c|c|c|c|c|c|c|c|c|}
\hline Traits & $\mathrm{PH}$ & $\mathrm{BP}$ & SB & BW & GOT & $\mathrm{SI}$ & SCY & $\mathrm{FL}$ & FS \\
\hline$\overline{B P}$ & $0.16^{*}$ & & & & & & & & \\
\hline SB & $0.63^{* *}$ & $0.17^{*}$ & & & & & & & \\
\hline BW & 0.05 & $0.21^{* *}$ & $0.07^{*}$ & & & & & & \\
\hline GOT & $0.34^{* *}$ & 0.02 & $0.22^{*}$ & -0.04 & & & & & \\
\hline SI & 0.08 & $0.25^{*}$ & 0.09 & $0.51^{* *}$ & -0.02 & & & & \\
\hline SCY & $0.29^{* *}$ & $0.54^{* *}$ & $0.39^{* *}$ & 0.18 & $0.28^{* *}$ & 0.02 & & & \\
\hline $\mathrm{FL}$ & $0.20^{*}$ & -0.04 & 0.06 & $0.20^{*}$ & $0.19^{*}$ & $0.17^{*}$ & $0.03^{*}$ & & \\
\hline FS & -0.16 & $0.19^{*}$ & $0.27^{*}$ & 0.12 & -0.06 & -0.05 & $0.33^{* *}$ & $-0.02^{*}$ & \\
\hline $\mathrm{FF}$ & $0.08^{*}$ & 0.04 & $0.17^{*}$ & $0.27^{*}$ & -0.14 & 0.26 & -0.06 & $0.11^{*}$ & -0.05 \\
\hline
\end{tabular}

PH: plant height, BP: the boll number per plant, SB: the number of sympodial branches per plant), BW: boll weight, Sl: seed index, SCY: seed cotton yield, FL: fiber length, FS: fiber strength and FF: fiber fineness. **: Highly significant $(P \leq 0.01)$, *: Significant $(P \leq 0.05)$ 
Table 3 The range of heritability of various traits of cotton grown in field condition according to the formula given by Burton (1953)

\begin{tabular}{lll}
\hline Traits & Heritability /\% & Status \\
\hline Plant height & 74.48 & High \\
The number of sympodial branches per plant & 48.06 & Medium \\
The number of bolls per plant & 53.87 & High \\
Boll weight & 46.66 & Medium \\
Ginning out turn & 90.65 & High \\
Seed index & 53.42 & High \\
Seed cotton yield & 54.56 & High \\
Fiber length & 52.95 & High \\
Fiber strength & 59.66 & High \\
Fiber fineness & 70.42 & High \\
\hline
\end{tabular}

High $>0.5$, Medium 0.2-0.5, Low $<0.2$

maximum value of 32.13 , followed by CIM-632, NIAB414 and A555 having mean estimates of, i.e., 26.53, 23.26, 23.13 correspondingly (Fig. 1-B). The cross of $\mathrm{VH}-367 \times$ CIM-632 had the highest mean value of 32.93 for the number of sympodial branches per plant, followed by NIAB-414 $\times$ IUB222, NIAB-414 $\times$ CIM-632 and A555 $\times$ IUB-222 which had mean values of, 32.53, $31,30.4$, and 28.2, respectively. $\mathrm{VH}-367$ showed the highest mean value of 23.13 followed by A555 (22.66), NIAB-414 (20.93) and IUB-222 (20.93) for number of sympodial branches per plant (Fig. 1-C). A555 × IUB-222 revealed the minimum mean value of 18.86 , whereas $\mathrm{VH}-367 \times$ NIAB-414 indicated maximum number of sympodial branches of 25.73. Genotype CIM-632 had minimum mean value for boll weight of $1.83 \mathrm{~g}$ whereas, VH-367 exhibited maximum mean value of $2.46 \mathrm{~g}$ (Fig. $1-\mathrm{D})$. IUB-222 $\times \mathrm{VH}-367$ revealed the lowest but VH$367 \times$ NIAB-414 showed maximum boll weight in all hybrids. NIAB-414 had minimum mean value for GOT if $38.03 \%$ while IUB-222 had maximum GOT of $42.32 \%$ (Fig. 1-E). NIAB $\times$ IUB-222 showed minimum value of $35.46 \%$ whilst hybrid VH-367 $\times$ CIM-632 revealed maximum GOT $46.33 \%$, followed by CIM-632 $\times \mathrm{VH}-367$, CIM-632 $\times$ A555 and A555 $\times$ NIAB-414 with estimates of $45.62 \%, 44.33 \%$ and $43.22 \%$, respectively.

The accessions NIAB-414 and A555 exhibited the minimum and maximum mean estimates of 5.07 and $5.64 \mathrm{~g}$, respectively, for 100-seed weight (Fig. 1-F). The hybrid of CIM- $632 \times \mathrm{VH}-367$ presented minimum seed index of $4.62 \mathrm{~g}$ whereas CIM-632 $\times$ A555 exhibited maximum mean value of $5.70 \mathrm{~g}$. While studying the seed cotton yield it was observed that IUB-222 revealed maximum mean value of $74.81 \mathrm{~g}$ (Fig. 1-G) whilst IUB-222 $\times$ A555 showed minimum seed cotton yield of $42.39 \mathrm{~g}$, but the hybrid VH-367 $\times$ CIM- 632 revealed the highest mean value of $80.17 \mathrm{~g}$ as being compared with A555 $\times$ IUB-222 and NIAB-414 $\times$ IUB-222 with mean values of 73.95 and $72.84 \mathrm{~g}$, respectively. CIM-632 indicated the lowest value of $24.71 \mathrm{~mm}$ for fiber length, while NIAB-414 had maximum of $26.86 \mathrm{~mm}$ (Fig. 1-H). Among the hybrids, A555 $\times \mathrm{VH}-376$ had minimum fiber length of $24.29 \mathrm{~mm}$, while the highest mean value $28.33 \mathrm{~mm}$ was shown by CIM-632 $\times$ NIAB-414. In case of fiber strength, VH-367 indicated maximum mean value of $29.83 \mathrm{~g}$.tex ${ }^{-1}$ followed by A555, NIAB-414 and CIM-632 with mean values of $26.35,26.28$ and 25.47 g.tex $^{-1}$, respectively (Fig. 1-I). Furthermore, CIM-632 $\times$ IUB-222 had minimum fiber strength of 23.29 g.tex ${ }^{-1}$, while $\mathrm{VH}-367 \times$ NIAB-414 revealed the highest value of 27.96 g.tex ${ }^{-1}$. IUB-222 exhibited the lowest value of $3.31 \mu \mathrm{g} \cdot \mathrm{inch}^{-1}$ for fiber fineness, while NIAB-414 had the highest mean value of $5.06 \mu \mathrm{g} \cdot$ inch $^{-1}$ (Fig. 1-J). While among the hybrids, IUB-222 $\times$ NIAB-414 exposed minimum mean value $3.23 \mu \mathrm{g} \cdot$ inch $^{-1}$, but NIAB-414 $\times$ IUB-222 had the highest mean value $5.44 \mu \mathrm{g} \cdot$ inch $^{-1}$.

\section{Discussion}

Plant height was positively linked with the number of sympodial branches per plant, the number of bolls per plant, GOT, seed cotton yield, staple length and fiber fineness (Table 2). Azhar and Ajmal (1999), Rao and Gopinath (2013) and Shahzad et al. (2015) also had similar findings. Tulasi et al. (2012) also observed positive association with GOT, fiber length and fineness. Heritability (BS) for plant height was $74.48 \%$ (Table 3). Kapoor and Kaushik (2003), Ahmad et al. (2011) and Baloch et al. (2015) also found high heritability of $94 \%$, $81 \%$ and $96.4 \%$ correspondingly for plant height. High heritability estimates indicated that selection for plant height can be effective. Boll numbers per plant had a positive association with plant height, boll weight, sympodial branches per plant, seed index, seed cotton yield, and fiber strength, respectively. Ahmad and Azhar (2000), Djaboutou et al. (2005), Gul et al. (2014), Magadum et al. (2012), Alkuddsi et al. (2013), and Farooq et al. (2014) also found same results. Heritability value for boll numbers per plant was 53.87\% (Table 3). Desalegn et al. (2009), Ahmad et al. (2011), Baloch et al. (2015), and Rathinavel et al. (2017) estimated 59\%, 88\%, $9 \% 3$, and $60.21 \%$ high broad sense heritability respectively, for bolls per plant. High estimates of heritability revealed that successful and effective selection can be helpful in the improvement of this trait.

The number of sympodial branches per plant had a positive relationship with plant height, number of bolls per plant, boll weight, seed cotton yield, GOT, fiber strength, and fiber fineness, respectively (Table 2). Pujer et al. (2014), Joshi et al. (2006) and Anandan (2009) indicated that the number of sympodial branches per plant positively correlated with seed cotton yield, plant height, 


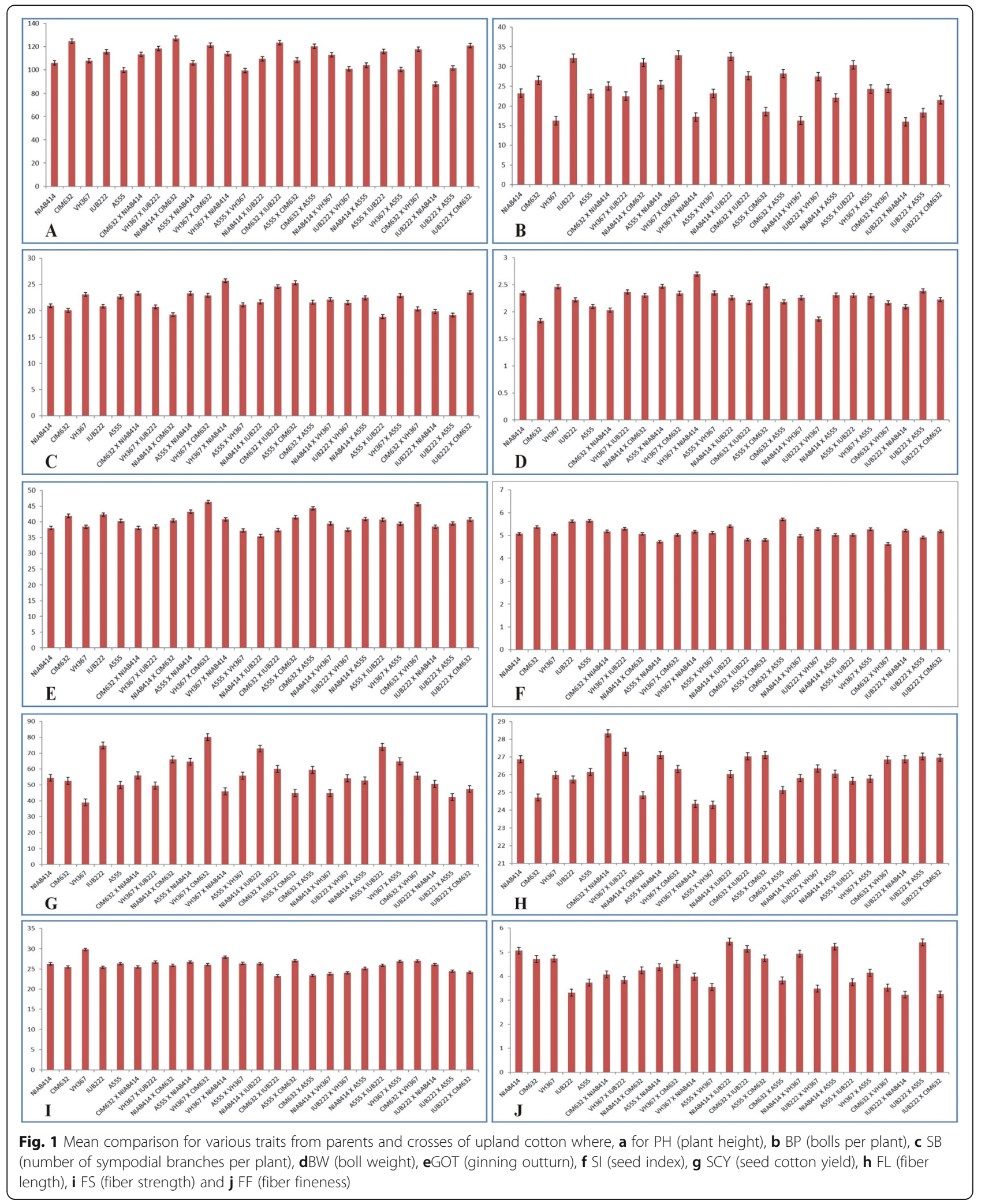

GOT and boll weight, respectively. Whereas, Killi et al. (2005) found that the number of sympodial branches per plant were positively linked with fiber strength. Rauf et al. (2004) also observed that the number of sympodial branches per plant had a positive relationship with the number of bolls per plant and fiber fineness, repectively. 
Moderate heritability for this trait was observed, i.e., 48.06\% (Table 3). Ahmed et al. (2006), Mustafa et al. (2007), Neelima and Reddy (2008), and Kulkarni et al. (2011) also observed medium heritability of 50.72\%, $59 \%, 61.30 \%$ and $43 \%$, respectively, for the number of sympodial branches per plant. Boll weight was positively linked with the number of bolls per plant, the number of sympodial branches per plant, 100-seed weight, staple length, and fiber fineness (Table 2). Jatt et al. (2007) revealed that boll weight had a positive association with yield of seed cotton. Abdullah et al. (2016), Shaheen and Yaseen (2014) observed that boll weight was positively correlated with fiber length, fiber fineness and the number of sympodial branches per plant, respectively. Do Thi et al. (2008) and Kale et al. (2007) reported that boll weight positively linked with seed index and the number of bolls per plantwhilst the heritability value was moderate of $46.66 \%$ (Table 3). Lu and Myers (2011), Naveed et al. (2004) and Ahmed et al. (2006) estimated \%57, $22 \%$ and $50.0 \%$ medium heritability respectively, for boll weight.

GOT had a positive relationship with plant height, seed cotton yield, sympodial branches per plant and fiber length, respectively (Table 2). Monicashree and Balu (2018), Pujer et al. (2014) and Chattha et al. (2013) observed that GOT had a positive linkage with plant height, the number of sympodial branches per plant and the yield of seed cotton. Shahzad et al. (2015) observed that GOT had a positive association with staple length. Heritability for GOT was $90.65 \%$ (Table 3). Devidas et al. (2017), Shahzad et al. (2015), Kumar and Katageri (2017), and Jarwar et al. (2018) found high heritability values of $72.5 \%, 80.73 \%, 90.0 \%$, and $85.46 \%$ for GOT. Seed index had a positive linkage with bolls per plant, boll weight and fiber length (Table 2). Patil (2010), Komala et al. (2018), Memon et al. (2017), Isong et al. (2017), Ashokkumar and Ravikesavan (2010), Shabbir et al. (2016), and Méndez-Natera et al. (2012) depicted similar findings. Heritability (B.S) for this trait was $53.42 \%$ (Table 3). Dhivya et al. (2014), Kaleri et al. (2016), Kumar and Katageri (2017), and Rajamani et al. (2015) estimated of $60.01 \%, 72.24 \%, 51.63 \%$ and $66.72 \%$ heritability correspondingly for seed index. Significant progress is possible through selection for this character.

Seed cotton yield had a positive association with plant height, the number of bolls per plant, the number of sympodial branches per plant, GOT, fiber length, and fiber strength, respectively (Table 2). Majeedano et al. (2014), Joshi et al. (2006), Gite et al. (2006), and Latif et al. (2015) indicated that seed cotton yield was positively linked with plant height, the number of sympodial branches per plant and the number of bolls per plant, respectively. Monisha et al. (2018) determined a positive correlation among GOT, fiber strength and seed cotton yield, respectively. Heritability value for seed cotton yield was 54.56\% (Table 3). Desalegn et al. (2009), Reddy and Reddy (2007), Hussain et al. (2010), Ullah et al. (2015), and Ahmad et al. (2011) estimated 61\%, 80\%, 50\%, 98\%, and $76 \%$ heritability, respectively, for this trait. This trait could be improved through selection process. Fiber length was positively linked with plant height, boll weight, GOT, seed index, fiber fineness and seed cotton yield. Fiber length had a negative correlation with fiber strength (Table 2). Ali and Awan (2009) and Echekwu (2001) indicated that fiber length was negatively associated with fiber strength, but Bechere et al. (2014) indicated that fiber length had a positive linkage with fibre strenth. Killi et al. (2005) determined a positive association among fiber length, plant height and seed cotton yield. Abbas et al. (2013) observed that staple length was positively associated with fiber fineness. Shabbir et al. (2016) observed that fiber length had a positive association with seed index. Khan and Azhar (2000) found that fiber length had a positive relationship with boll weight. Heritability in broad sense for fiber length was 52.95\% (Table 3). Killi et al. (2005), Abbas et al. (2013), Khan and Azhar (2000) and Ahmed et al. (2006) found 94\%, $52 \%, 96 \%$, and $56 \%$ heritability estimates, respectively, for fiber length. It is concluded that selection can be useful for fiber length. Fiber strength had a positive association with boll numbers per plant, the number of sympodial branches per plant, and seed cotton yield whereas fiber strength had a negative linkage with fiber length (Table 2). Ahmad and Azhar (2000), Thiyagu et al. (2010) and Farooq et al. (2014) found that fiber strength was positively correlated with the yield of seed cotton and the number of bolls per plant. Ali and Awan (2009) revealed that fiber strength was negatively associated with fiber length. For this trait the heritability value was 59.66\% (Table 3). Desalegn et al. (2009), Killi et al. (2005), Shahzad et al. (2015), Rasheed et al. (2009) and Khokhar et al. (2017) determined 33\%, 73\%, 62\%, 70\%, and $68 \%$ heritability for this character. Fiber fineness was positively correlated with plant height, the number of sympodial branches per plant, boll weight, and staple length (Table 2). Ali and Awan (2009), Zeng and Meredith (2009), Tang and Xiao (2014) and Yaqoob et al. (2016) found a positive relationship between fiber fineness and staple length. Abbas et al. (2013) and Altaher and Singh (2003) revealed that fiber fineness had a positive linkage with plant height, the number of sympodial branches per plant. Abdullah et al. (2016) reported that fiber fineness was positively correlated with boll weight. The heritability value for fiber fineness was $70.42 \%$ (Table 3). Hendawi et al. (1999) and Lu et al. (2002) estimated $67 \%$ and $73 \%$ heritability respectively, for fiber fineness. 


\section{Conclusion}

The correlation results from this study would be helpful to breed cotton cultivars for good yield and fine quality characters. Broad sense of heritability in high status provides the strong evidence that selection in early generations can improve the performance of these traits.

\section{Abbreviations}

GDP: Gross domestic product; PH: Plant height; BP: Bolls per plant; SB: Number of sympodial branches per plant; BW: Boll weight; GOT: Ginning outturn; SI: Seed index; SCY: Seed cotton yield; FL: Fiber length; FS: Fiber strength; FF: Fiber fineness; BS: Broad sense; RCBD: Randomized complete block design; ANOVA: Analysis of variance

\section{Authors' contributions}

Mustafa $\mathrm{N}$ and Rehman A conducted experiment and wrote the initial draft of the manuscript. Azhar MT played role in designing and statistics of the experiment, besides Azhar MT supervised Mustafa N for master studies. Du XM proofread the manuscript before submission to JCR. The authors read and approved the final manuscript.

\section{Funding}

This work was supported by the Department of Plant Breeding and Genetics, Faculty of Agriculture, University of Agriculture, Faisalabad, Pakistan.

\section{Availability of data and materials}

Not applicable.

\section{Ethics approval and consent to participate}

Not applicable.

\section{Consent for publication}

Not applicable.

\section{Competing interests}

Authors declare that they have no conflict of interest for the publication of the manuscript.

\section{Author details}

${ }^{1}$ Zhengzhou Research Base, State Key Laboratory of Cotton Biology, Zhengzhou University, Zhengzhou 450001, China. ${ }^{2}$ Institute of Cotton Research, Chinese Academy of Agricultural Sciences/State Key Laboratory of Cotton Biology, Anyang 455000, China. ${ }^{3}$ Department of Plant Breeding and Genetics, University of Agriculture Faisalabad, Faisalabad 38040, Pakistan. ${ }^{4}$ School of Agriculture Sciences, Zhengzhou University, Zhengzhou 450001, China.

Received: 17 March 2020 Accepted: 6 August 2020

Published online: 26 August 2020

\section{References}

Abbas H, Mahmood A, Ali Q, et al. Genetic variability, heritability, genetic advance and correlation studies in cotton (Gossypium hirsutum L.). Int Res J Microbiol. 2013;4(6):156-61.

Abdullah M, Numan M, Shafique MS, et al. Genetic variability and interrelationship of various agronomic traits using correlation and path analysis in cotton (Gossypium hirsutum L.). Acad J Agri Res. 2016;4(6):315-8. https://doi.org/10.15413/ajar.2016.0154.

Ahmad M, Azhar FM. Genetic correlation and path coefficient analysis of oil and protein contents and other quantitative characters in $F_{2}$ generation of Gossypium hirsutum L. Pak J Biol Sci. 2000;3(6):1049-51.

Ahmad M, Khan NU, Muhammad F, et al. Shaheen S: genetic potential and heritability studies for some polygenic traits in cotton (Gossypium hirsutum L. ). Pak J Bot. 2011:43(3):1713-8.

Ahmed HM, Kandhro MM, Laghari S, Abro S. Heritability and genetic advance as selection indicators for improvement in cotton (Gossypium hirsutum L.). J Biol Sci. 2006;6(1):96-9.

Ali MA, Awan SI. Inheritance pattern of seed and lint traits in cotton (Gossypium hirsutum). Int J Agric Biol. 2009;11(1):44-8.
Alkuddsi Y, Rao MG, Patil S, et al. Correlation and path coefficient analysis between seed cotton yield and its attributing characters in intra hirsutum cotton hybrids. Mol Plant Breed. 2013;4(6):214-9. https://doi.org/10.5376/ mpb.2013.04.0026.

Altaher A, Singh R. Yield component analysis in upland cotton (Gossypium hirsutum L.). J Indian Soc Cotton Improv. 2003;28(3):151-7.

Anandan A. Studies on choice of characters for breeding for seed cotton yield and fibre quality traits in cotton. Crop Improv. 2009;36(1):35-7.

Ashokkumar K, Ravikesavan R. Genetic studies of correlation and path coefficient analysis for seed oil, yield and fibre quality traits in cotton (G. hirsutum L.). Aust J Basic App Sci. 2010;4(11):5496-9.

Azhar F, Ajmal S. Diallel analysis of oil content in seed of Gossypium hirsutum L. [Pakistan]. J Genet Breed. 1999:53(1):19-23.

Baloch M, Baloch A, Baloch M, et al. Association and heritability analysis for yield and fiber traits in promising genotypes of cotton (Gossypium hirsutum L.) Sindh Uni Res J. 2015;47(2):303-6.

Bechere E, Zeng L, Boykin D. Correlation and path-coefficient analyses of lint yield and other traits in upland cotton (Gossypium hirsutum L.). Crop Improv. 2014;28(6):852-70. https://doi.org/10.1080/15427528.2014.955621.

Burton GW. Devane EH. Estimating heritability in tall fescue (Festuca arundinacea) from replicated clonal material 1. Agron J. 1953:45(10):478-81.

Chattha WS, Farooq J, Ahmad A, et al. Correlation analysis of quality and yield contributing traits in upland cotton (Gossypium hirsutum L.). Int J Modern Agri. 2013;2:95-101.

Desalegn Z, Ratanadilok N, Kaveeta R. Correlation and heritability for yield and fiber quality parameters of Ethiopian cotton (Gossypium hirsutum L.) estimated from 15 (diallel) crosses. Kasetsart J. 2009:43:1-11.

Devidas AA, Narayan SA, Prakash PN. Study of genetic variability, heritability and genetic advance in some genotypes of Egyptian cotton (Gossypium barbadense L.). J Global Biosci. 2017:6(4):4954-7.

Dhivya R, Amalabalu P, Pushpa R, Kavithamani D. Variability, heritability and genetic advance in upland cotton (Gossypium hirsutum L.). African J Plant Sci. 2014;8(1):1-5. https://doi.org/10.5897/AJPS2013.1099.

Djaboutou C, Alabı S, Echewku C, Orakwue F. Variability and interrelationship of some agronomic and fibre quality traits in multi-adversity cotton (Gossypium hirsitum L.). Agric Trop Subtrop. 2005:38(3-4):7-12.

Do Thi HA, Ravikesavan R, lyanar K. Genetic advance and heritability as a selection index for improvement of yield and quality in cotton. J Cotton Res Develop. 2008;22(1):14-8

Dowd MK, Boykin DL, Meredith WR Jr, et al. Fatty acid profiles of cottonseed genotypes from the national cotton variety trials. J Cotton Sci. 2010;14:64-73.

Echekwu C. Correlations and correlated responses in upland cotton (Gossypium hirsutum L.). Tropicultura. 2001;19(4):210-2.

Farooq J, Anwar M, Riaz M, et al. Correlation and path coefficient analysis of earliness, fiber quality and yield contributing traits in cotton (Gossypium hirsutum L.). J Anim Plant Sci. 2014;24(3):781-90.

Gite V, Misal M, Kalpande H. Correlation and path analysis in cotton (Gossypium hirsutum L.). J Cotton Res Develop. 2006;20(1):51-4.

Economic Adviser's Wing, Finance Division, Government of Pakistan. Pakistan Economic Survey 2018-2019. Retrived from http://www.finance.gov.pk/survey/ chapters_19/Economic Survey_2018_19.pdf. 2019. Accessed 3 Mar 2020.

Gul S, Khan N, Batool S, et al. Genotype by environment interaction and association of morpho-yield variables in upland cotton. J Anim Plant Sci. 2014;24(1):262-71.

Haq A, Khan N, Raza $H$, et al. Genetic attributes of $F_{3}$ populations and their parental lines in upland cotton. J Anim Plant Sci. 2017;27(2):655-66.

Hendawi F, Radi M, Abdel-Hamid A, Ismail R. Inheritance of fiber traits in some cotton crosses. Egypt J Agron. 1999;21:15-36.

Lu HJ, Myers GO. Combining abilities and inheritance of yield components in influential upland cotton varieties. Aust J Crop Sci. 2011;5(4):384-90.

Hussain S, Nawab N, Ali MA, et al. Evolution of performance, genetic divergence and character association of some polygenic traits in upland cotton. J Agric Soc Sci. 2010;6(4):79-82

Isong A, Balu PA, Ramakrishnan P. Association and principal component analysis of yield and its components in cultivated cotton. Electr J Plant Breed. 2017; 8(3):857-64. https://doi.org/10.5958/0975-928X.2017.00140.5.

Jarwar AH, Wang X, Wang L, et al. Genetic advancement, variability and heritability in upland cotton (Gossypium hirsutum L.). J Envir Agric Sci. 2018;6: 24-31

Jatt T, Abro H, Larik A, Soomro Z. Performance of different cotton varieties under the climatic conditions of Jamshoro. Pak J Bot. 2007;39(7):2427-30. 
Joshi H, Chovatia P, Mehta D. Genetic variability, character association and component analysis in upland cotton. Indian J Agric Res. 2006;40(4):302-5.

Kale U, Kalpande H, Annapurve S, Gite V. Yield components analysis in American cotton (Gossypium hirsutum L.). Madras Agric J. 2007:94(7-12):156-61.

Kaleri AA, Baloch AW, Baloch M, et al. Heritability and correlation analysis in Bt and non-Bt cotton (Gossypium hirsutum L.) genotypes. Pure and App Bio. 2016;5(4):906-12. https://doi.org/10.19045/bspab.2016.50114.

Kapoor C, Kaushik S. Variability, heritability and genetic advance studies in cotton (Gossypium hirsutum L.). J Cotton Res Dev. 2003;17:240-2.

Khan Al, Azhar FM. Estimates of heritabilities and pattern of association among different characters of Gossypium hirsutum L. Pak J Agric Sci. 2000;37:7-10.

Khokhar ES, Shakeel A, Maqbool MA, et al. Genetic study of cotton (Gossypium hirsutum I.) genotypes for different agronomic, yield and quality traits. Pak J Agric Res. 2017;30(4):363-72. https://doi.org/10.17582/journal.pjar/2017/30.4. 363.372.

Killi F, Efe L, Mustafayev S. Genetic and environmental variability in yield, yield components and lint quality traits of cotton. Int J Agri Biol. 2005;7(6):100710.

Komala M, Ganesan NM, Kumar M. Genetic variability, heritability and correlation analysis in $F_{2}$ populations of Ratoon upland cotton hybrids. Int J Agric Envi Biotech. 2018;11(6):815-27. https://doi.org/10.30954/0974-1712.12.2018.2.

Kulkarni A, Nanda H, Patil S. Study of genetic parameters on yield, yield contributing and fibre quality characters in upland cotton (Gossypium hirsutum L.). J Cotton Res Dev. 2011;25(1):22-4.

Kumar NM, Katageri I. Genetic variability and heritability study in $F_{2}$ population of Gossypium barbadense L. cotton for yield and its components. Int J Curr Microbiol App Sci. 2017;6(6):975-83. https://doi.org/10.20546/ijcmas.2017.606. 114.

Kwon S, Torrie J. Heritability and interrelationship among traits of two soybean populations. Crop Sci. 1964;4(2):196-8.

Latif A, Bilal M, Hussain SB, Ahmad F. Estimation of genetic divergence, association, direct and indirect effects of yield with other attributes in cotton (Gossypium hirsutum L.) using biplot correlation and path coefficient analysis. Trop Plant Res. 2015;2(2):120-6.

Lu Y, Zhen Z, Zhen G, Ju P. Genetic stability of fibre quality in upland cotton. Cotton Sci. 2002;14:67-70.

Magadum S, Banerjee U, Ravikesavan R, et al. Association analysis of yield and fibre quality characters in interspecific population of cotton (Gossypium spp.). J Crop Sci Biotech. 2012;15(3):239-43. https://doi.org/10.1007/s12892-0120027-9.

Majeedano MS, Ahsaan M, Somroo A, Channa A. Heritability and correlation estimates for some yield traits of Gossypium hirsutum. Am Res Thoughts. 2014;1:781-90.

Memon S, Gandahi AWBN, Yasir TA, et al. Evaluation of genetic divergence, character associations and path analysis in upland cotton genotypes. Pure App Bio. 2017;6(4):1516-21. https://doi.org/10.19045/bspab.2017.600163.

Méndez-Natera JR, Rondón A, Hernández J, Merazo-Pinto JF. Genetic studies in upland cotton. III. Genetic parameters, correlation and path analysis. Sabrao J Breed Genet. 2012:44(1):112-28.

Minitab IN. Minitab 16 statistical software. State College: Minitab, Inc.; 2010.

Monicashree C, Balu PA. Association and path analysis studies of yield and fibre quality traits in intraspecific hybrids of upland cotton (Gossypium hirsutum L.) Res J Agric Sci. 2018;9(5):1101-6.

Monisha K, Premalatha N, Sakthivel N, Kumar M. Genetic variability and correlation studies in upland cotton (Gossypium hirsutum L). Elect J Plant Breed. 2018;9(3):1053-9. https://doi.org/10.5958/0975-928X.2018.00131.X.

Mukoyi F, Gasura E, Makunde G. Implications of correlations and genotype by environment interactions among cotton traits. Afr Crop Sci J. 2018;26(2):21935. https://doi.org/10.4314/acsj.v26i2.5.

Mustafa A, Elsheikh Y, Babiker E. Genetic variability and character association and selection criteria in cotton (Gossypium hirsutum L). Sudan J Agric Res. 2007:8:43-50.

Naveed M, Azhar F, Ali A. Estimates of heritabilities and correlations among seed cotton yield and its components in Gossypium hirsutum L. Int J Agric Biol. 2004:6(4):712-4.

Neelima S, Reddy VC. Genetic parameters of yield and fibre quality traits in American cotton (Gossypium hirsutum L.). Indian J Agric Res. 2008;42(1):67-70.

Patil $H$. Variability and correlation analysis by using various quantitative traits in released Bt cotton hybrids. J Cotton Res Dev. 2010;24(2):141-4.

Pujer SK, Siwach S, Sangwan R, et al. Correlation and path coefficient analysis for yield and fibre quality traits in upland cotton (Gossypium hirsutum L). J Cotton Res Dev. 2014;28:214-6.
Rajamani S, Sumalatha P, Gopinath M. Studies on genetic parameters of seed cotton yield and fibre traits in upland cotton (Gossypium hirsutum L.). J Cotton Res Dev. 2015;29(1):36-8.

Rao P, Gopinath M. Association analysis of yield and fibre quality characters in upland cotton (Gossypium hirsutum L.). Aust J Basic App Sci. 2013;7(8):787-90.

Rasheed A, Malik W, Khan A, et al. Genetic evaluation of fiber yield and yield components in fifteen cotton (Gossypium hirsutum) genotypes. Int J Agric Biol. 2009;11:581-5.

Rathinavel K, Kavitha H, Priyadharshini C. Assessment of genetic variability and correlation analysis of seed and seed cotton yield attributing traits of tetraploid cotton genotypes (G. hirsutum L.). Electr J Plant Breed. 2017;8(4): 1275-83. https://doi.org/10.5958/0975-928X.2017.00182.X.

Rauf S, Khan TM, Sadaqat HA, Khan Al. Correlation and path coefficient analysis of yield components in cotton (Gossypium hirsutum L.). Int J Agric Biol. 2004; 6(4):686-8.

Reddy YR, Reddy C. Genetic variability for yield components and fibre characters in cotton. Plant Arch. 2007;7(2):759-61.

Shabbir RH, Bashir QA, Shakeel A, et al. Genetic divergence assessment in upland cotton (Gossypium hirsutum L.) using various statistical tools. J Global Inno Agric Soc Sci. 2016;4(2):62-9. https://doi.org/10.22194/JGIASS/4.2.744.

Shaheen M, Yaseen M. Path analysis based on genetic association of yield components in upland cotton. Life Sci Int J. 2014;8(1):2988-94.

Shahzad MT, ljaz F, Khan O, et al. Correlation, Path Analysis \& Heritability among some yield and fibre related traits of Gossypium hirsutum L. Cotton Genom Genet. 2015;6(4):1-7. https://doi.org/10.5376/cgg.2015.06.0004 .

Shar T, Baloch M, Arain M, et al. Phenotypic associations, regression coefficients and heritability estimates for quantitative and fiber quality traits in upland cotton genotypes. Pak J Agric Eng VetSci. 2017;33(2):142-52.

Singh P. Cotton breeding. New Delhi: Kalyani Publishers; 2004. p. 295.

Steel RGD, Torrie JH. Dickey DA principles and procedures of statistics: a biometrical approach. 3rd ed. New York: McGraw Hill; 1997.

Stewart L, Rossi J. Using cotton byproducts in beef cattle diets. Bulletin 1311. Cooperative Extension, the University of Georgia College of Agricultural and Environmental Sciences. 2010; 1-8. http://cotton.tamu.edu/General\%2 OProduction/Georgia\%20Cotton\%20Byproducts\%20for\%20Beef\%20Cattle\%2 OB\%201311_2.pdf. Accessed 27 Feb 2020.

Tang F, Xiao W. Genetic association of within-boll yield components and boll morphological traits with fibre properties in upland cotton (Gossypium hirsutum L.). Plant Breed. 2014;133(4):521-9. https://doi.org/10.1111/pbr. 12176.

Teklewold A, Jayaramaiah H, Jagadeesh BN. Correlations and path analysis of physio-morphological characters of sunflower (Helianthus annuus L.) as related to breeding method. Helia. 2000;23(32):105-14.

Thiyagu K, Nadarajan N, Rajarathinam S, et al. Association and path analysis for seed cotton yield improvement in interspecific crosses of cotton (Gossypium spp). Electr J Plant Breed. 2010;1(4):1001-5.

Tulasi J, Lal MA, Murthy J, Rani YA. Correlation and path analysis in american cotton. Electr J Plant Breed. 2012;3(4):1005-8.

Ullah K, Usman Z, Khan N, et al. Genetic diversity for yield and related traits in upland cotton genotypes. Pak J Agric Res. 2015;28(2):118-25.

Yaqoob M, Fiaz S, ljaz B. Correlation analysis for yield and fiber quality traits in upland cotton. Commun Plant Sc. 2016;6(3/4):55-60.

Zeng L, Meredith WR. Associations among lint yield, yield components, and fiber properties in an introgressed population of cotton. Crop Sci. 2009;49(5): 1647-54.

Ready to submit your research? Choose BMC and benefit from:

- fast, convenient online submission

- thorough peer review by experienced researchers in your field

- rapid publication on acceptance

- support for research data, including large and complex data types

- gold Open Access which fosters wider collaboration and increased citations

- maximum visibility for your research: over $100 \mathrm{M}$ website views per year

At $\mathrm{BMC}$, research is always in progress.

Learn more biomedcentral.com/submission 